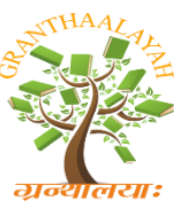

\author{
INTERNATIONAL JOURNAL OF RESEARCH - \\ GRANTHAALAYAH \\ A knowledge Repository
}

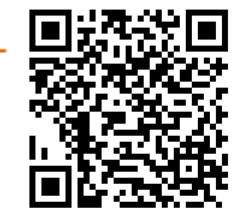

Science

\title{
SURVEY OF CHANGE IN HUMIDITY, TEMPERATURE AND ILLUMINANCE BY USING DIFFERENT MATERIALS FOR ROOF CONSTRUCTION
}

\author{
Vishal Gadgihalli ${ }^{* 1}$, MeenaY.R ${ }^{2}$, Lohit ${ }^{1}$, Prabin Neupane ${ }^{1}$, Raghavendra Prasad Havanje \\ Dinakar $^{3}$ \\ ${ }^{* 1}$ UG Student, Department of civil engineering, Jain University, Bangalore, India \\ ${ }^{2}$ Assistant Professor, Department of civil engineering, Jain University, Bangalore, India \\ ${ }^{3}$ Research Assistant, Department of civil engineering, Jain University, Bangalore, India
}

\begin{abstract}
A roof is uppermost part of building or shelter which plays a predominant role in protecting inner elements and living things inside structure, this protects against weather, rain, snow, heat, wind and sunlight. The protection properties of roof vary by composites with which the roof is made. In this paper analysis of temperature, humidity and illuminance properties variation due to different types of roofs, the survey made on different roofs such as R.C.C, Asbestos sheets, planks and shack type of roofs for 24 hours are compared to reading that are obtained by open place reading without any roof. This survey clearly represented that readings gradually increases when sun is at his highest point and reduces to zero in the absence of sun. This survey also revealed that using asbestos sheet roof will increases humidity of roof eventually and by using shank roof reduces the temperature, humidity, and lux values passing in to building. Hence this says that although shank roof are less strength roof compared to all roofs these can be used in arid region to reduce interior temperature and humidity, although asbestos sheets are thin layered these can be used in places where humidity and temperature is required compared to temperature and humidity outside the building.
\end{abstract}

Keywords: R.C.C Roof; Asbestos Sheet Roof; Planked Roof; Shank Roof; Humidity; Illuminance, and Interior Temperature.

Cite This Article: H. Babitha Rani, Shadakshara Swamy, A. L. Bharath, Raghavendra Prasad Havanje Dinakar, and A. V. Raghu. (2017). "SURVEY OF CHANGE IN HUMIDITY, TEMPERATURE AND ILLUMINANCE BY USING DIFFERENT MATERIALS FOR ROOF CONSTRUCTION." International Journal of Research - Granthaalayah, 5(11), 390-399. https://doi.org/10.29121/granthaalayah.v5.111.2017.2372.

\section{Introduction}

A roof places an importance role for interior protection of building or structure by weather, rain, snow, heat, wind and sunlight. This also increases the aesthetic appearance by different types of 
roofs; the components used in making the roofs place a predominant role in strength, stability and resistance properties of roof. The word also denotes the framing or structure which supports the coverage [1].

The R.C.C roofs majorly consist of steel and concrete, the steel withstanding tensile strength and concrete resisting the compressive strength. This can be made into almost any shape and size FRP composites and construction parameters [2].

The ultimate failure caused due to yielding or failure of the rebar when bending or shear stresses exceed the strength of reinforcement or by bond failure between the concrete and the rebar [3].

Asbestos roofs are made of asbestos sheets, the asbestos powder is a set of six naturally occurring silicate minerals, [4] long Chrystal, thin fibrous crystals, with each visible fiber composed of millions of microscopic "fibrils" that can be released by abrasion and other processes [5].

Plank is manufactured by burning the clay molding in plank shape for highest degree of temperature. These planks are constructed as per codes. Native people of Pacific North West maintained a distinct respect for Ceder and the value it had held for many generations [6]

Shank roofs are made by data palm branches, dried grass, leaves of coconut and other herb's which are arranged and tied in proper manner supported by bamboo reinforcement at bottom that can withstand the compressive load exerted by dead load caused of leaves and herbs used to cover giving extra support.

The author has surveyed the temperature, illuminance, and humidity variation inside the structure whose roofs consisted of R.C.C, Plank, Asbestos sheet and shack types of roofs, this survey was conducted for 24 hours and the reading were noted at every hourly interval of time.

This helps prediction of type of roof to be used for any specific area whose temperature, humidity, varies by location of construction site.

\section{Methodology}

Firstly buildings must be selected which are roofed by R.C.C, asbestos sheet, burnt clay plank and shank, these must be selected in such a way that only one window and a door is fixed, roof must be fully covered without any damage or cracks. As the distance between the buildings increase the number of measuring instruments requires also increase hence it will be better to choose location of buildings which are near as much as possible. In this work to measure the readings Mini environment quality meter-850070 is used. An alarm is used to take reading visiting different building to take readings. Before start taking readings a temporary mark must be marked on floor in building to overcome the confusion of placing the instrument.

Readings must be taken carefully with every interval time of 1 hour at every building. So for completion of this survey 24 readings are obtained for each type of roof. 


\section{Results and Discussions}

\begin{tabular}{|l|l|l|l|}
\hline \multicolumn{5}{|c|}{ Reading obtained at open sky without any obstacles } \\
\hline Time & LUX & $\%$ RH & ${ }^{*}$ C \\
\hline $11: 12$ & 1793 & 46.8 & 34.12 \\
\hline $12: 08$ & 1844 & 47.31 & 35.62 \\
\hline $13: 13$ & 1952 & 49.21 & 36.12 \\
\hline $14: 04$ & 1985 & 52.08 & 36.94 \\
\hline $15: 10$ & 1932 & 48.94 & 35.12 \\
\hline $16: 07$ & 1812 & 48.09 & 34.39 \\
\hline $17: 14$ & 1432 & 37.12 & 33.08 \\
\hline $18: 07$ & 889 & 34.87 & 32.31 \\
\hline $19: 12$ & 273 & 32.94 & 27.14 \\
\hline $20: 11$ & 42 & 30.11 & 26.29 \\
\hline $21: 09$ & 7 & 28.98 & 25.23 \\
\hline $22: 13$ & 0 & 27.11 & 23.51 \\
\hline $23: 04$ & 0 & 26.84 & 22.94 \\
\hline $0: 12$ & 0 & 27.91 & 22.69 \\
\hline $1: 05$ & 0 & 28.52 & 22.14 \\
\hline $2: 13$ & 0 & 29.71 & 21.88 \\
\hline $3: 09$ & 0 & 32.96 & 21.67 \\
\hline $4: 04$ & 0 & 34.92 & 21.79 \\
\hline $5: 09$ & 26 & 36.16 & 22.33 \\
\hline $6: 08$ & 48 & 37.54 & 24.67 \\
\hline $7: 04$ & 326 & 39.13 & 26.18 \\
\hline $8: 06$ & 954 & 41.42 & 27.83 \\
\hline $9: 11$ & 1467 & 43.85 & 31.1 \\
\hline $10: 06$ & 1688 & 44.76 & 32.26 \\
\hline & & & \\
\hline
\end{tabular}

\begin{tabular}{|l|l|l|l|}
\hline \multicolumn{4}{|c|}{ Reading obtained under R.C.C roof building } \\
\hline TIME & LUX & \%RH & *C \\
\hline $11: 14$ & 214 & 47.32 & 32.19 \\
\hline $12: 12$ & 267 & 48.08 & 32.85 \\
\hline $13: 19$ & 317 & 50.34 & 33.17 \\
\hline $14: 16$ & 334 & 51.05 & 33.78 \\
\hline $15: 03$ & 327 & 50.88 & 33.23 \\
\hline $16: 13$ & 306 & 47.74 & 30.79 \\
\hline $17: 08$ & 254 & 45.12 & 29.34 \\
\hline $18: 17$ & 181 & 38.91 & 27.63 \\
\hline $19: 03$ & 102 & 35.67 & 27.39 \\
\hline $20: 08$ & 19 & 32.89 & 26.87 \\
\hline $21: 01$ & 2 & 29.76 & 26.11 \\
\hline $22: 09$ & 0 & 29.44 & 24.56 \\
\hline $23: 11$ & 0 & 28.98 & 24.14 \\
\hline $0: 17$ & 0 & 28.73 & 23.87 \\
\hline
\end{tabular}




\begin{tabular}{|l|l|l|l|}
\hline $1: 10$ & 0 & 28.65 & 23.66 \\
\hline $2: 06$ & 0 & 28.41 & 23.41 \\
\hline $3: 17$ & 0 & 28.07 & 22.86 \\
\hline $4: 12$ & 0 & 27.85 & 23.12 \\
\hline $5: 02$ & 0 & 28.49 & 23.89 \\
\hline $6: 14$ & 14 & 30.16 & 25.45 \\
\hline $7: 13$ & 132 & 37.13 & 27.84 \\
\hline $8: 11$ & 169 & 38.89 & 29.21 \\
\hline $9: 02$ & 182 & 40.54 & 30.06 \\
\hline $10: 13$ & 198 & 44.02 & 31.56 \\
\hline
\end{tabular}

\section{Reading obtained under asbestos sheet roof building}

\begin{tabular}{|c|c|c|c|}
\hline TIME & LUX & $\%$ RH & ${ }^{*} \mathrm{C}$ \\
\hline $11: 22$ & 253 & 48.48 & 33.61 \\
\hline $12: 24$ & 318 & 49.87 & 34.28 \\
\hline $13: 27$ & 356 & 52.02 & 34.89 \\
\hline $14: 23$ & 381 & 52.54 & 35.43 \\
\hline $15: 25$ & 364 & 51.62 & 34.06 \\
\hline $16: 21$ & 329 & 49.12 & 32.73 \\
\hline $17: 26$ & 272 & 47.11 & 31.07 \\
\hline $18: 25$ & 192 & 41.02 & 29.28 \\
\hline $19: 20$ & 117 & 38.31 & 28.14 \\
\hline $20: 19$ & 31 & 36.26 & 27.65 \\
\hline $21: 23$ & 3 & 34.98 & 27.12 \\
\hline $22: 24$ & 0 & 34.42 & 26.47 \\
\hline $23: 18$ & 0 & 33.79 & 26.19 \\
\hline $0: 21$ & 0 & 33.3 & 25.86 \\
\hline $1: 17$ & 0 & 32.96 & 25.32 \\
\hline $2: 24$ & 0 & 32.71 & 24.87 \\
\hline $3: 22$ & 0 & 32.58 & 24.31 \\
\hline $4: 19$ & 0 & 31.93 & 25.07 \\
\hline $5: 17$ & 11 & 33.1 & 25.73 \\
\hline $6: 23$ & 27 & 35.46 & 26.49 \\
\hline $7: 22$ & 164 & 39.35 & 28.61 \\
\hline $8: 19$ & 192 & 41.62 & 29.93 \\
\hline $9: 23$ & 217 & 43.29 & 30.87 \\
\hline $10: 20$ & 231 & 45.86 & 32.04 \\
\hline
\end{tabular}

\begin{tabular}{|l|l|l|l|}
\hline \multicolumn{5}{|c|}{ Reading obtained under clay planks roof building } \\
\hline TIME & LUX & \% RH & *C \\
\hline $11: 29$ & 241 & 47.84 & 32.76 \\
\hline $12: 30$ & 289 & 49.07 & 33.31 \\
\hline $13: 36$ & 332 & 51.22 & 33.87 \\
\hline $14: 34$ & 357 & 51.9 & 34.14 \\
\hline $15: 39$ & 344 & 51.32 & 33.62 \\
\hline
\end{tabular}




\begin{tabular}{|l|l|l|l|}
\hline $16: 29$ & 315 & 48.38 & 31.21 \\
\hline $17: 35$ & 264 & 46.11 & 29.74 \\
\hline $18: 33$ & 187 & 39.49 & 28.32 \\
\hline $19: 28$ & 108 & 36.87 & 27.63 \\
\hline $20: 31$ & 28 & 34.16 & 27.18 \\
\hline $21: 32$ & 2 & 32.94 & 26.43 \\
\hline $22: 37$ & 0 & 32.59 & 25.86 \\
\hline $23: 29$ & 0 & 32.21 & 25.29 \\
\hline $0: 30$ & 0 & 31.88 & 24.77 \\
\hline $1: 32$ & 0 & 31.63 & 24.24 \\
\hline $2: 33$ & 0 & 31.45 & 24.02 \\
\hline $3: 30$ & 0 & 30.97 & 23.73 \\
\hline $4: 28$ & 0 & 30.74 & 24.13 \\
\hline $5: 36$ & 3 & 31.32 & 24.52 \\
\hline $6: 29$ & 21 & 33.81 & 26.02 \\
\hline $7: 34$ & 148 & 38.16 & 28.29 \\
\hline $8: 27$ & 176 & 40.38 & 29.56 \\
\hline $9: 31$ & 199 & 42.46 & 30.41 \\
\hline $10: 36$ & 214 & 44.92 & 31.74 \\
\hline
\end{tabular}

\section{Readings obtained under shank roof building}

\begin{tabular}{|c|c|c|c|}
\hline TIME & LUX & $\%$ RH & $* \mathrm{C}$ \\
\hline 11:44 & 192 & 46.87 & 31.86 \\
\hline $12: 42$ & 244 & 47.41 & 32.13 \\
\hline $13: 49$ & 283 & 48.63 & 32.58 \\
\hline $14: 45$ & 311 & 49.15 & 33.29 \\
\hline $15: 41$ & 295 & 49.92 & 32.65 \\
\hline $16: 42$ & 279 & 46.22 & 30.03 \\
\hline $17: 43$ & 236 & 44.9 & 28.89 \\
\hline 18:39 & 153 & 38.21 & 27.32 \\
\hline $19: 38$ & 84 & 34.72 & 26.96 \\
\hline $20: 42$ & 0 & 30.67 & 26.35 \\
\hline $21: 45$ & 0 & 28.14 & 25.86 \\
\hline $22: 50$ & 0 & 27.78 & 24.13 \\
\hline $23: 38$ & 0 & 27.34 & 23.79 \\
\hline $0: 42$ & 0 & 26.97 & 23.53 \\
\hline $1: 45$ & 0 & 26.83 & 23.09 \\
\hline $2: 40$ & 0 & 26.49 & 22.84 \\
\hline $3: 39$ & 0 & 26.13 & 22.56 \\
\hline $4: 36$ & 0 & 25.56 & 22.73 \\
\hline $5: 48$ & 0 & 27.14 & 23.07 \\
\hline $6: 41$ & 0 & 28.67 & 24.69 \\
\hline $7: 47$ & 96 & 34.45 & 26.28 \\
\hline
\end{tabular}




\begin{tabular}{|l|l|l|l|}
\hline $8: 36$ & 131 & 36.26 & 27.54 \\
\hline $9: 47$ & 158 & 37.97 & 28.31 \\
\hline $10: 42$ & 166 & 42.16 & 30.54 \\
\hline
\end{tabular}

Reading by open sky
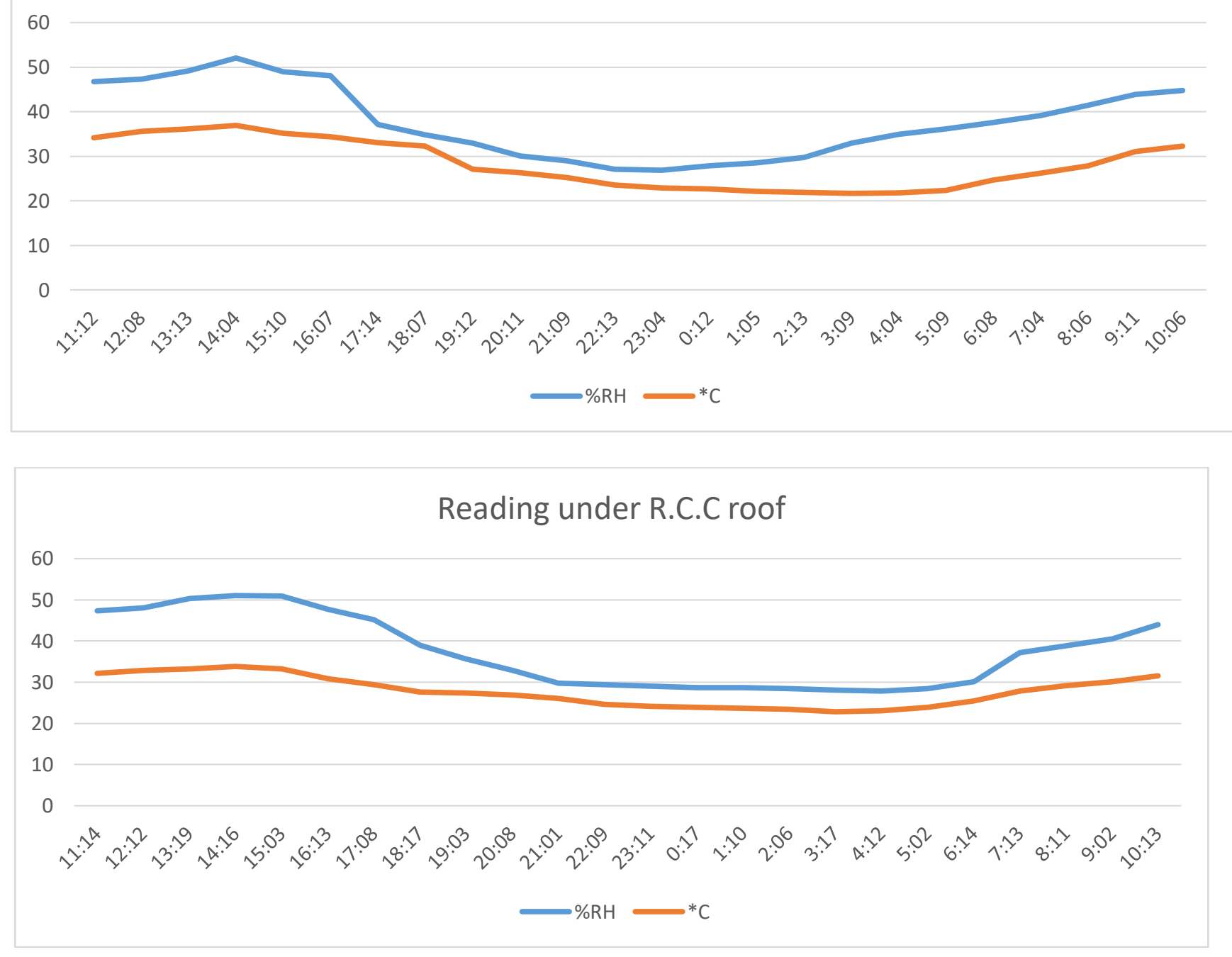


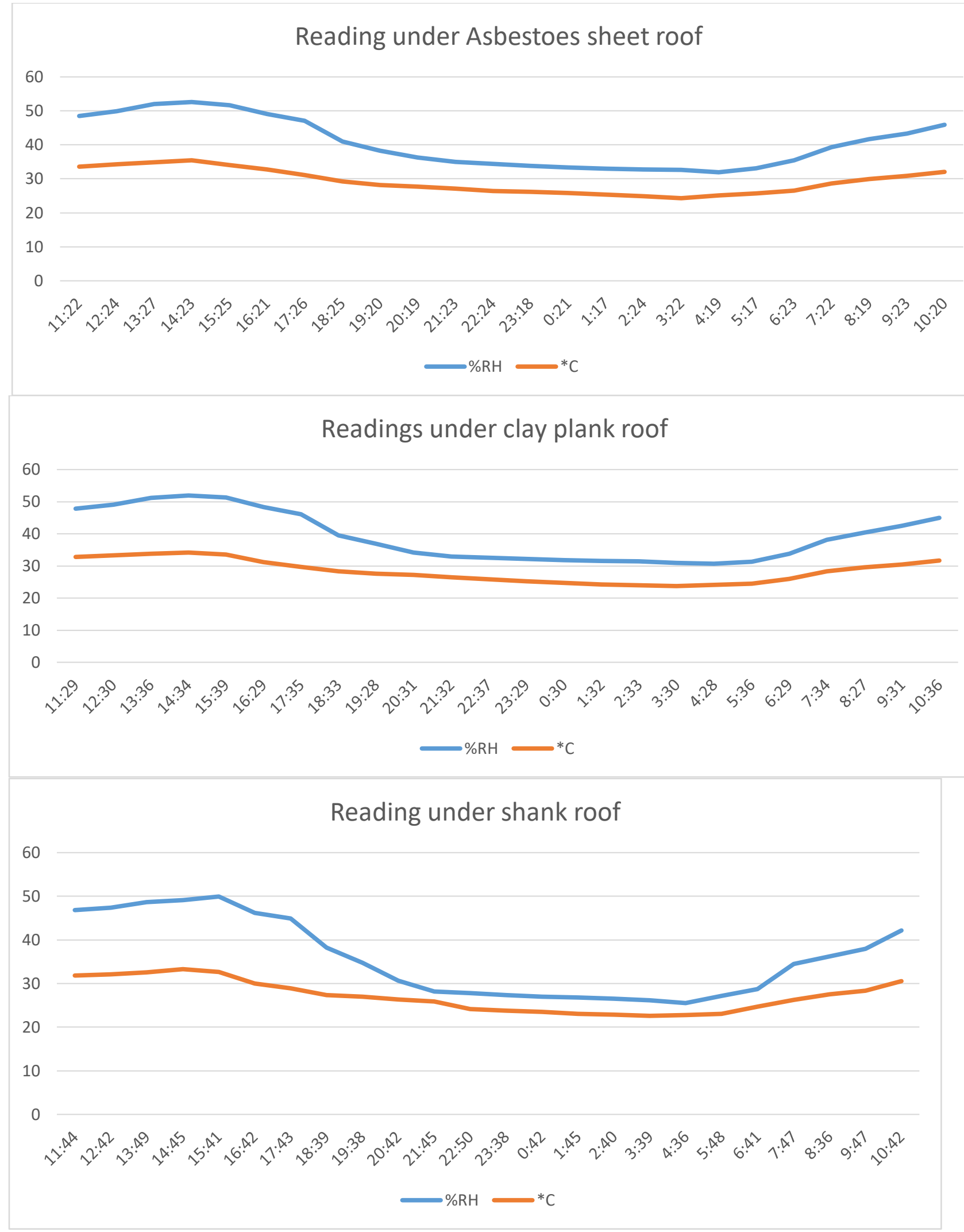




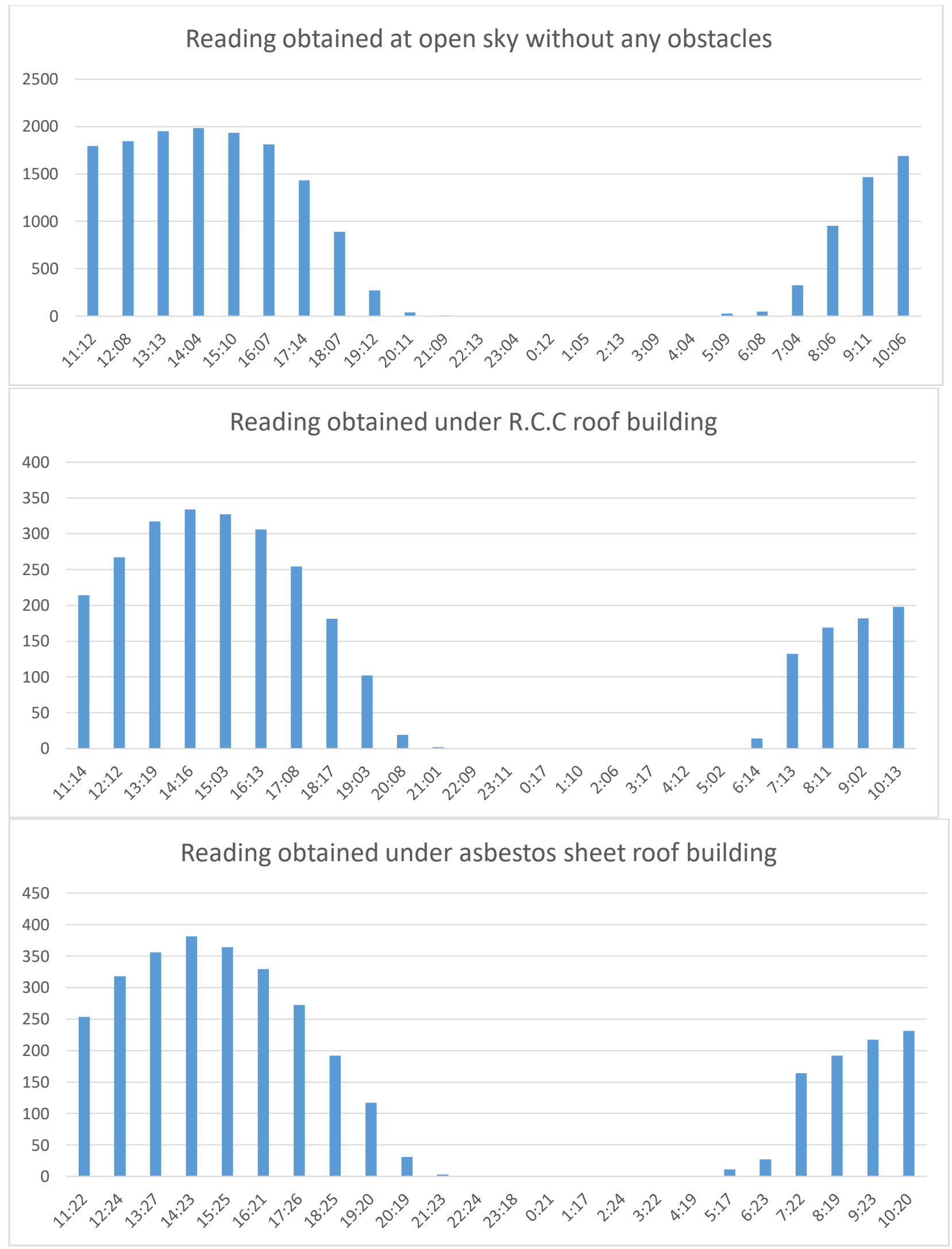




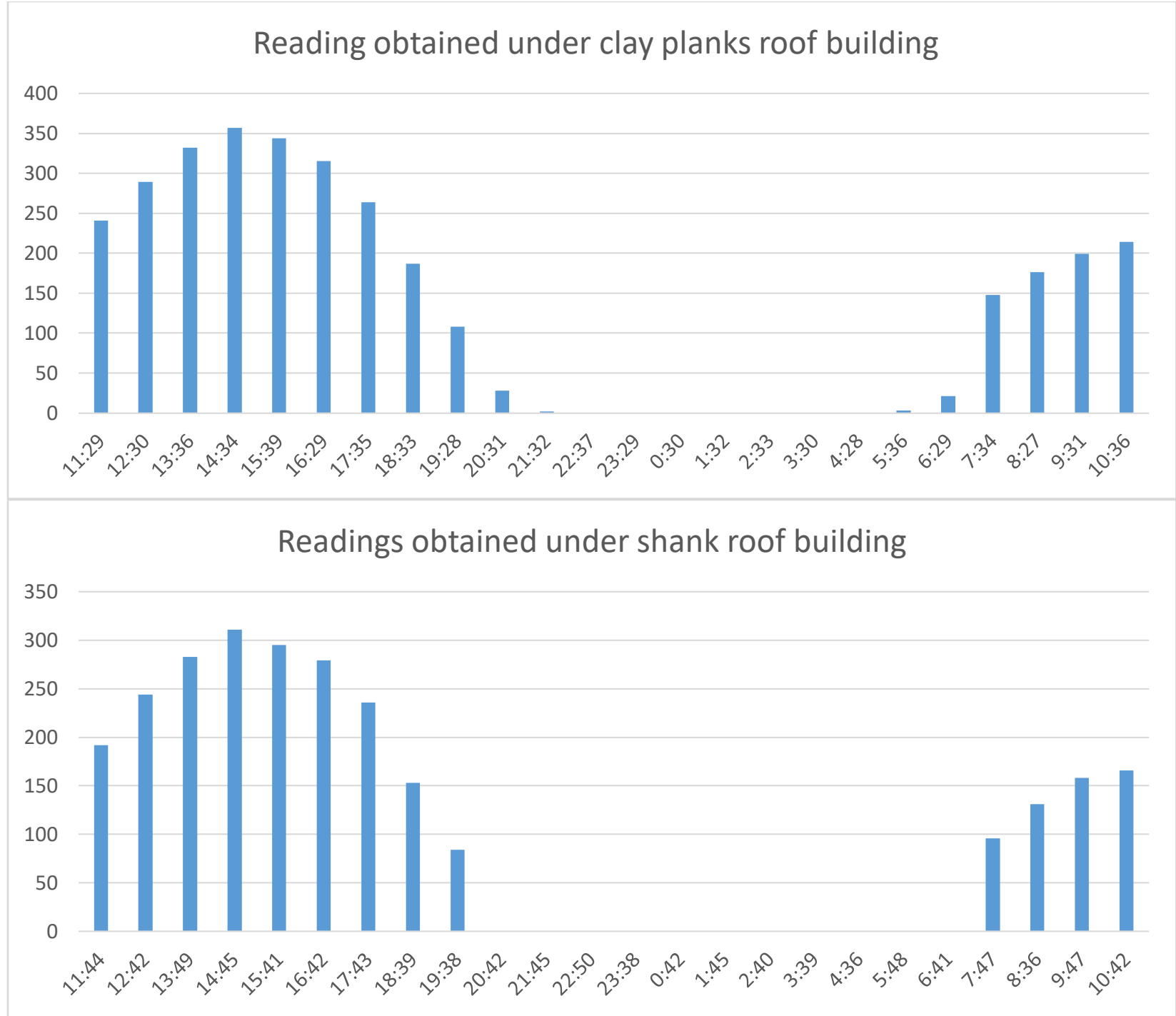

\section{Conclusions and Recommendations}

From the above survey it is clear that by using asbestos sheets as roofing material to building will increase humidity and temperature inside the building. As asbestos are made of six different fibrous minerals such as crocidolite, anthophyllite, actinolite, amosite, chrysotile and tremolite, these minerals will not allow humidity and temperature pass through it hence he heat will be trapped inside the building increasing its interior temperature.

By using shank roof which is built up by palm and coconut leaves supported by bamboo sticks to withstand the compressive strength caused by load of roof will help in reducing the humidity and temperature inside the building. As materials used to make shank leaves allow humidity and temperature of interior building to pass through them easily to the outer space.

Although using R.C.C roofs and clay planked roof gives more stability and resistance towards rainfall, cold etc, these will not bring any considerable amount of change in interior temperature, humidity and illumination compared to outer space. 


\section{Acknowledgements}

Special thanks to Nagaraj Sitaram sir for providing Mini Environment Quality Meter with trust. Even thanks for HitheshNagothu, for helping me in completing this work successfully. And I also thank my parents, teachers, friends and all elders who supported me.

\section{References}

[1] Whitney, William Dwight and Benjamin E Smith. The century dictionary and cyclopedia, Vol 6, New York: Century Co., 1901.5,221. Print.

[2] "FRP Materials", FRP composites and construction parameters.

[3] Janowski,A.; Nagrodzka. Godycka,K; Szulwic, J.; Ziolkowski,P.(2016). "Remote sensing and photogrammetry technigue in diagnostics of concrete structures". Computers and concrete.18 (3);405-420.doi:10.12989/cac.2016.18.3.405. Retrieved 2016-12-14.

[4] Alleman, James E; Brooke T (July 1997).”Asbestos revisited”. Scientific American. 277:54-57. Bibcode: 1997 SciAm.277a.70A.doi:10.1038/Scientific American 0797-70. Archived from the original on 3 june 2010. Retrieved 26 November 2010.

[5] Gee, David; Greenberg, Morris (9 January 2002). "Astestos: From magic to malevolent mineral". Late lessons from early warnings: the precautionary principle 1896-2000. Copenhagen: EEA (22):52-63.ISBN92-9167-323-4. Retrieved 20 April 2010.

[6] "Ceder: Tree of life to the North West Coast Indians," by Hilary Stewart describes and illustrates the harvesting of individual planks from living trees.

*Corresponding author.

E-mail address: gauravkumar.shaha@ gmail.com 